\title{
Prototipe Mesin CNC 3 Axis Sederhana untuk IKM Mainan Edukasi Berbahan Kayu
}

\author{
Andhika Estiyono, Arie Kurniawan, dan Ari Dwi Krisbianto \\ Departemen Desain Produk Industri, \\ Fakultas Arsitektur Desain dan Perencanaan, \\ Institut Teknologi Sepuluh Nopember \\ Email:x5modeller@gmail.com
}

\begin{abstract}
Abstrak - Pembuatan mainan pendidikan (educational toys) puzzle secara manual dimana dalam usahanya untuk mencapai kepresisian bentuk masih menemui banyak kesulitan. Kesulitan yang dialami meliputi pembuatan masih terpisah satu-persatu di tiap bentuknya, bentuk yang satu dengan yang lain yang serupa namun memiliki ukuran yang tidak seragam dan kebutuhan proses produksi yang lebih cepat. Metode yang ditawarkan adalah proses pembuatan dan pemotongan dengan menggunakan mesin $\mathrm{CNC}$ dengan sekali proses pengerjaan. Diharapkan dengan menggunakan mesin $\mathrm{CNC}$ woodworking kebutuhan dalam pembuatan bentuk mainan yang presisi dapat tercapai dan dapat dilakukan dengan lebih cepat sehingga menambah produktifitas IKM.
\end{abstract}

Kata Kunci: CNC, presisi, puzzle, mainan kayu, IKM

Abstract - There are still many adversities to achieve precision on puzzle educational toys making. The complications are separate making one by one in its form, dissimilarity in its size and to quicken production process. Manufacturing and cutting process using CNC machine is offered method for its solution. Woodworking CNC machine are able to do one process at a time, more precision, faster and able to gain small-medium industries (IKM) productivity.

Keyword: CNC, precision, puzzle, wooden toys, IKM

\section{PENDAHULUAN}

Mainan puzzle adalah jenis mainan teka-teki yang berupa komponen-komponen bidang dengan bentuk dan ukuran yang seragam secara keseluruhan dan/atau memiliki beberapa bentuk yang berbeda dengan perbedaan ukuran di tiap bidangnya serta mempunyai ketebalan yang sama [1]. Mainan puzzle bisa dikatakan permainan dua dimensi meskipun secara fisik mempunyai ketebalan material. Bahan yang umum digunakan IKM berupa bahan papan tipis, bisa MDF, triplek maupun solidwood.

Proses pembuatan dan pemotongan bahan untuk membuat mainan pendidikan puzzle dilakukan dengan menggunakan mesin pemotong jigsaw [2]. Komponen bentuk mainan puzzle, dibuat dengan memotong satu persatu bagian puzzle yang sebelumnya sudah dimal dan disatukan di akhir ketika masing-masing bentuk sudah terbuat dalam sebuah papan berbingkai. Dalam penyatuan bagiannya masih harus melakukan penyetelan agar masing-masing bagian dapat masuk ke dalam bingkai dan bisa bersinggungan dengan tepat dengan masing-masing bentuk di dekatnya. Penyetelan berupa proses pemotongan tipis jika masih terlalu banyak tepian bidang yang bersinggungan dan melakukan pengamplasan jika bidang tepian yang bersinggungan sedikit. Namun dengan jumlah komponen bentuk puzzle yang banyak sangat membutuhkan waktu dalam penyelesaian satu set mainan puzzle.

Proses penyetelan agar dapat tepat bersinggungan menjadi lebih banyak mengubah bentuk sehingga tiap bentuk bidang komponen puzzle menjadi tidak sama bentuk dan ukuran di tiap unit bentuknya. Hal ini menyebabkan tidak dapat dilakukan tukar posisi bidang karena bentukan unit bidang puzzle dengan bentuk dan ukuran yang sudah disetel untuk posisi tertentu hanya untuk posisi tersebut. Perbedaan bentuk dan ukuran ini, meskipun hanya berbeda kurang dari satu milimeter menyebabkan bidang puzzle tidak dapat masuk bersinggungan masuk ke dalam papan bingkai dan menimbulkan kesulitan ketika digunakan bermain anak-anak [3]. Sebaliknya agar kondisi di atas dapat diminimalisir maka toleransi persinggungan dilebarkan. Dampak yang muncul mengakibatkan unit antar bidang menjadi tidak presisi dan memunculkan jarak. Akibat jarak ini mainan puzzle tidak bisa rapat dan saling mengunci.

\section{METODE PENELITIAN}

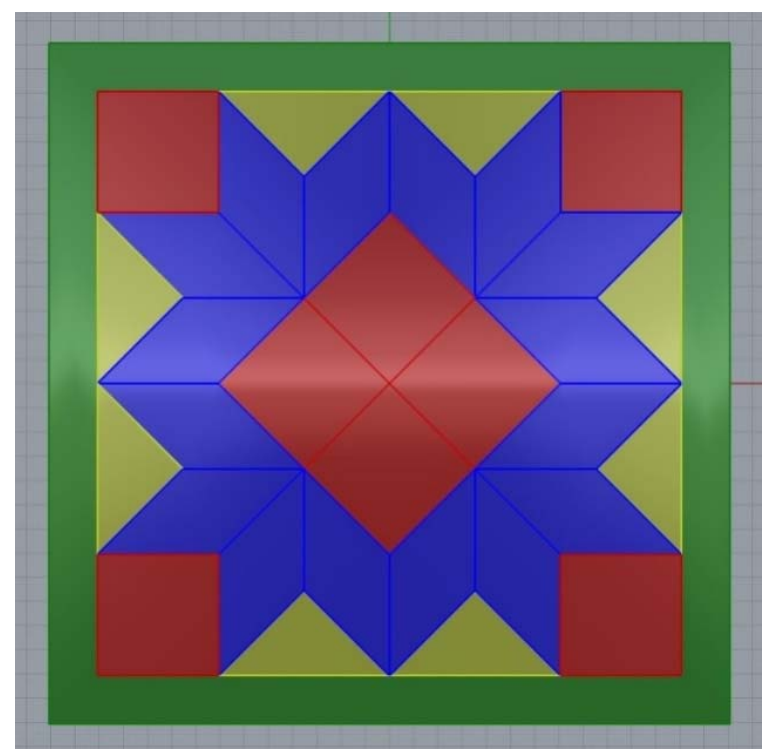

Gambar 1 Tiga Dimensi pola mainan puzzle.

Penelitian dilakukan dengan cara eksperimen uji kerja menggunakan mesin $\mathrm{CNC}$ yang sudah dibuat dengan metode Integrated Digital Design. Diawali dengan proses perencanaan melalui CAD dengan membuat gambar tiga dimensi pola mainan puzzle (Gambar 1).

Dari masing-masing unit bentuk dan ukurannya kemudian dikelompokkan pada lokasi pola potong (Gambar 2). 
Pengelompokan rencana potong dimaksudkan agar tools mesin $\mathrm{CNC}$ sudah terset untuk memotong sesedikit mungkin material yang dibutuhkan [4] dan dalam satu rangkaian alur potong sekaligus sudah memisahkan dua tepian bidang sehingga waktu yang dibutuhkan untuk pemotongan menjadi lebih singkat. Toleransi yang dipakai adalah 0,5 milimeter, sedikit lebih besar dari standar toleransi persinggunan untuk komponen industri yang sejumlah 0,2 milimeter karena untuk mengejar kemudahan lepaspasang unit mainan dan mengejar keseragaman bentuk dan ukuran tanpa proses penyetelan.

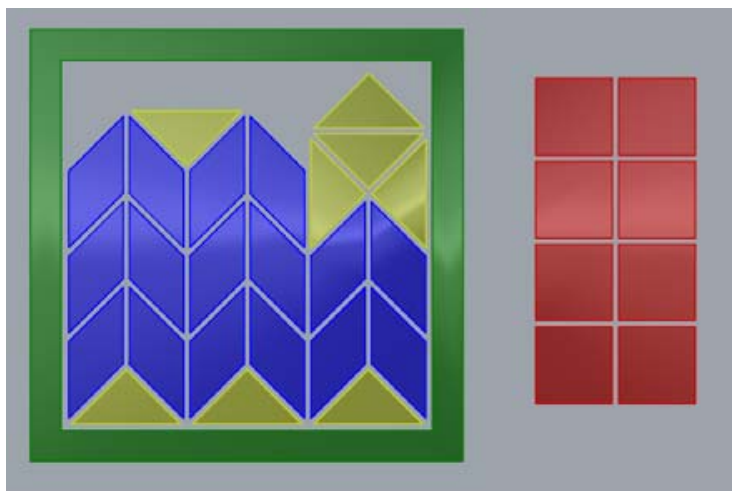

Gambar 2 Pengelompokan pola potong

\section{HASIL DAN PEMBAHASAN}

\section{Dimensi CNC}

Mesin CNC mempunyai luasan bidang kerja (bed) dengan ukuran XY $1200 \mathrm{~mm}$ x $1200 \mathrm{~mm}$. Ukuran ini didapatkan dari luasan material lembaran yang mudah diperoleh di pasaran yaitu 1220 $\mathrm{mm}$ x $2440 \mathrm{~mm}$ kemudian dibagi menjadi dua bagian luasan. Setelah melalui observasi di lapangan luasan mainan yang dikerjakan mempunyai dimensi XY yang tidak lebih dari $500 \mathrm{~mm}$ x $500 \mathrm{~mm}$ sehingga untuk pengerjaan lebih dari satu masih bisa dikerjakan sekali waktu.

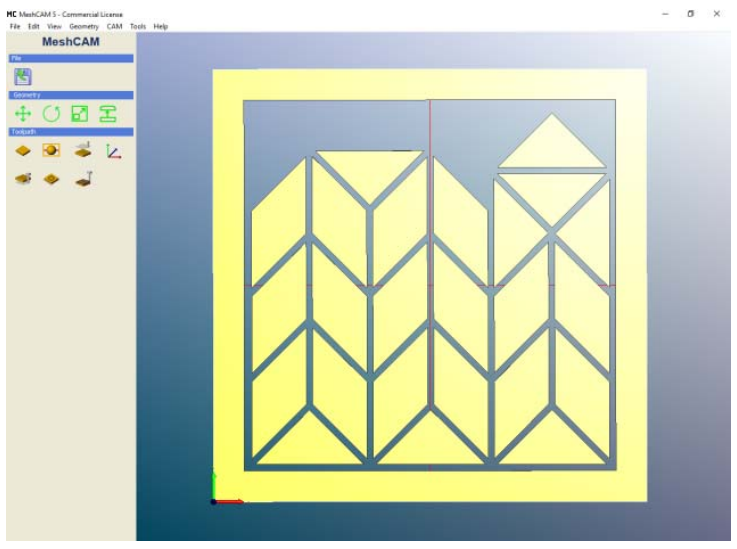

Gambar 3 Operasi software MeshCAM.

\section{Uji Kerja CNC}

\section{Tahap perancangan}

Gambar tiga dimensi diolah dalam aplikasi software MeshCAM untuk menentukan tools yang akan dipakai beserta rencana pemotongan (Gambar 3). Pemotongan di-setting dengan menentukan titik nol pada bidang dan sesuai rencana akan dilakukan dalam dua langkah kedalaman (depth=2.5 mm). Sistem pemotongan yang akan dipakai adalah waterline. Material yang dipakai mempunyai ketebalan 5 milimeter dengan bahan MDF yang mempunyai tekstur halus dan kepadatan yang cukup. Menggunakan mata pisau (tool) ujung datar (endmill) dengan ukuran 3.175 milimeter (EM $3.175 \mathrm{~mm}$ ) berbahan Tungsten sehingga jarak pada saat pengolompokan pola bentuk adalah lebih besar dari diameter putar tool $(3.175<\mathrm{x}=4 \mathrm{~mm})$. Kecepatan putar spindle yang digunakan adalah $300 \mathrm{~mm} / \mathrm{s}(\mathrm{F}=300,00)$.

Langkah berikutnya dilakukan proses rekayasa G-Code sebagai keluaran software CAM untuk menentukan alur potong bidang mana yang harus terpotong terlebih dahulu dan mana yang belum agar masih ada pemegang bidang agar tidak terpotong seluruhnya secara langsung dan lepas. Rekayasa G-Code menggunakan software G-Code Optimizer dengan memindah angka-angka koordinat di urutan kerja.

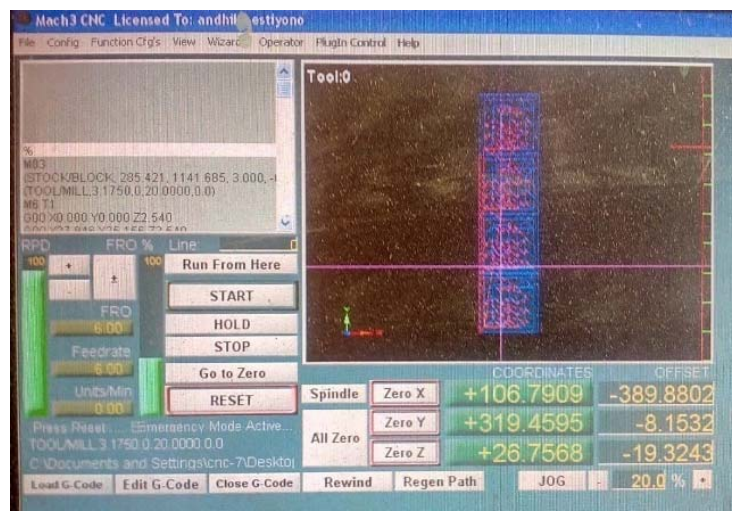

Gambar 4. Setting dengan menggunakan software Mach3.

\section{Tahap pemotongan}

Diawali dengan memasang material pada bidang kerja $\mathrm{CNC}$ (bed CNC). Material yang digunakan berdimensi XYZ $281.42 \mathrm{~mm} \mathrm{x}$ $281.42 \mathrm{~mm}$ x $3.00 \mathrm{~mm}$ adalah dimensi total boundingbox material yang sudah dikelompokkan sesuai pola dengan diberi spasi bidang lebih sejumlah 20 milimeter sebagai tepian pemegang material yang tidak kena potong di bagian tepi-tepi bidang. Bidang material potong tidak boleh bergeser atau berpindah posisi. Setelah material potong terpasang sempurna, langkah berikutnya menentukan titik awal potong XYZ ujung tool terhadap bidang kerja kemudian mengeset pada software pelaksana Mach3 bahwa pada kedudukan itu mempunyai angka nol (All zero: Zero X; Zero Y; Zero Z) kemudian mesin siap dijalankan (Gambar 4).

\section{Hasil}

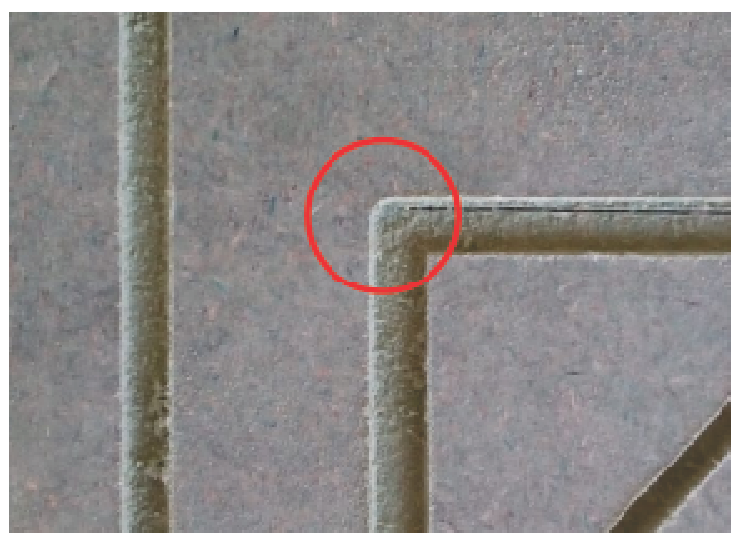

Gambar 5 Fillet garis lengkung hasil potong bagian dalam siku. Uji coba menggunakan mdf anti air $3 \mathrm{~mm}$ 
Hasil potong pada bagian sudut dalam bingkai dengan sudut $90^{\circ}$ terdapat fillet garis lengkung karena tool dengan diameter 3.175 milimeter tidak dapat menjangkau ujung sudut tegak lurus bagian dalam bingkai. Hal ini menyebabkan ujung unit bidang puzzle yang runcing dan terpotong sempurna dari bagian luar yang bersinggungan dengan sudut siku bingkai tidak dapat masuk ke dalam bingkai jika dipasang keseluruhan (Gambar 5).

Dilakukan improvisasi langsung dengan menyetel manual bagian sudut unit bidang puzzle agar bisa masuk pada sudut bingkai dengan diamplas dan dipingul.

Pada saat pemasangan keseluruhan unit bidang puzzle ke dalam bingkai mainan, unit bidang tidak dapat masuk. Dilakukan pengecekan ukuran tiap unit bidang ternyata ada perbedaan panjang dan lebar dari hasil potongan dengan rencana gambar tiga dimensi (3D). Untuk pengecekan menggunakan bentuk yang paling sederhana yaitu bentuk geometri persegi dengan ukuran XY 49.975 $\mathrm{mm}$ x $49.975 \mathrm{~mm}$ mempunyai ukuran hasil potongan XY 49.85 $\mathrm{mm} \times 50.12 \mathrm{~mm}$.

\section{Perbaikan/Improvement}

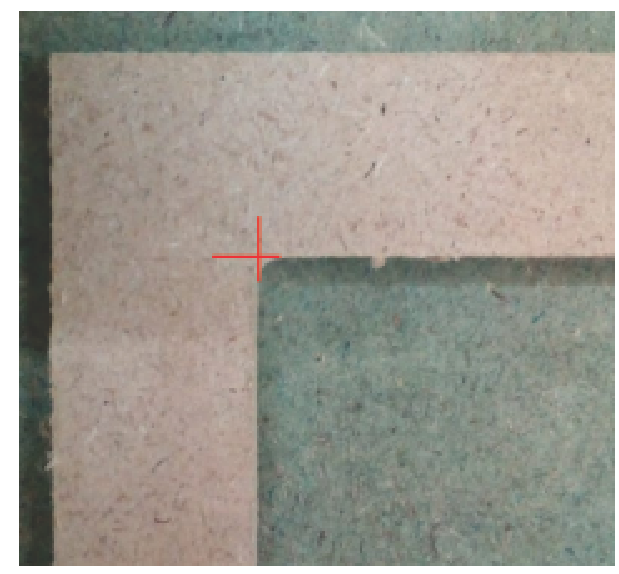

Gambar 6 Sudut bingkai dengan radius.

Terdapat opsi penyelesaian untuk mengatasi masalah hasil potongan sudut dari tool mesin CNC. Hasil potongan sudut tidak bisa bersudut tegak-lurus karena beradius mengikuti diameter tool CNC yang digunakan (Gambar 6). Sudut terdapat fillet dengan radius sama seperti tool yaitu $+/-3 \mathrm{~mm}$ (diameter tool $=3.175 \mathrm{~mm}$ ) sehingga jika tetap mempertahankan tetap bersudut tegak-lurus maka harus dipotong manual pada sudut bingkainya.

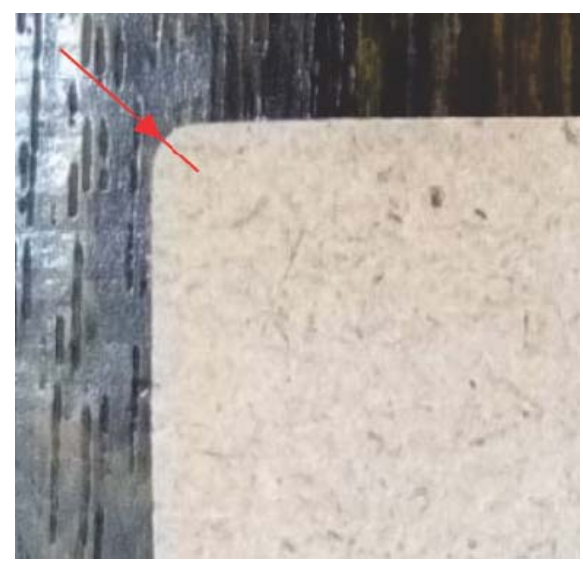

Gambar 7 Sudut bingkai dengan radius.
Opsi berikutnya adalah dengan membiarkan sudut tetap beradius sesuai dengan hasil potong tool CNC namun melakukan sedikit perubahan pada unit bangun isian bingkai pada bidang yang berhimpit dengan sudut tersebut. Perubahan berupa mem-fillet tiap sudut bangun (Gambar 7) sehingga tidak perlu dilakukan lagi perbaikan manual. Opsi yang dipilh adalah opsi yang kedua.

Bangun isian yang disesuaikan dengan di-fillet adalah bangun persegi karena bangun persegi letaknya berada di sudut-sudut bingkai. Radius fillet dari bangun persegi adalah $2.5 \mathrm{~mm}$ didapatkan dari radius bingkai $3 \mathrm{~mm}$ dikurangi toleransi jarak 0,5 $\mathrm{mm}$. Selanjutnya dilakukan proses cutting dengan hasil yang cukup rapat namun masih ada jarak pada persinggungan tertentu (Gambar 8)

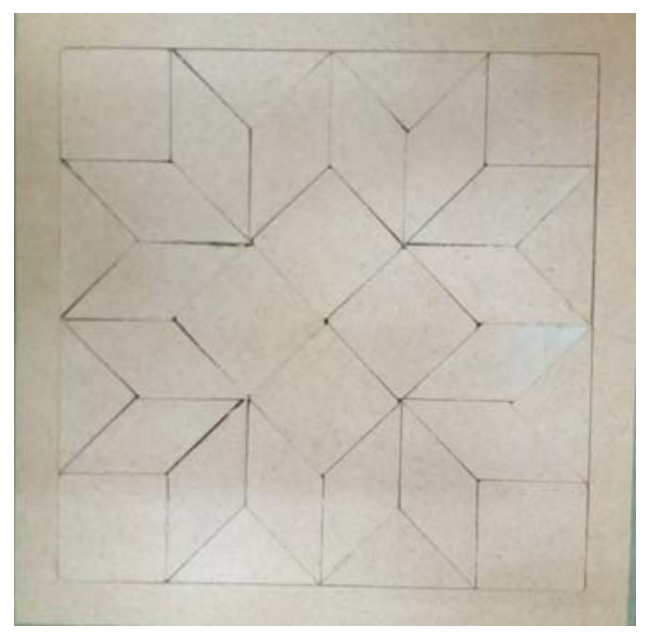

Gambar 8 Hasil potongan perbaikan.

\section{KESIMPULAN}

Masih perlu dilakukan perbaikan dan improvement dari hasil pemotongan unit bidang mainan puzzle. Usaha yang masih dilakukan adalah menyamakan hasil potongan material bidang unit mainan dengan geometri yang ada di gambar rencana tiga dimensi pada software CAD. Improvements yang harus dilakukan antara lain:

1. Melakukan penyesuaian dengan mengubah gambar rencana tiga dimensi (3D) untuk langsung disesuaikan dengan lengkungan yang kongruen dengan sudut bingkai mainan yang ter-fillet.

2. Melakukan pengecekan kembali pada bidang kerja (bed) $\mathrm{CNC}$ apakah sudah cukup kuat kunciannya dengan struktur rangka CNC dan melakukan pengecekan pada pemegang material bidang potong.

3. Melakukan rekalibrasi mesin $\mathrm{CNC}$

4. Menentukan urutan potongan bidang $\mathrm{CNC}$ agar hasil potongannya bisa satu persatu terpotong dengan baik tanpa merusak bidang potong yang lain.

\section{DAFTAR PUSTAKA}

[1] Fuadiyah, Nidho. (2013). Upaya Meningkatkan Pengenalan Geometri dengan Permainan Puzzle Bervariasi pada Kelompok 
Andhika Estiyono, Arie Kurniawan, dan Ari Dwi Krisbianto

Prototipe Mesin CNC 3 Axis Sederhana untuk IKM Mainan Edukasi Berbahan Kayu

B TK Al-Hikmah Randudongkal-Pemalang, Skripsi Program Pendidikan Anak Usia Dini, IKIP PGRI Semarang

[2] Home-Douglas, P. (1995). The Art Of Woodworking-Wooden Toys and Crafts.

[3] Muloke, I. C., Ismanto, A. Y., \& Bataha, Y. (2017). Pengaruh Alat Permainan Edukatif (Puzzle) Terhadap Perkembangan
Kognitif Anak Usia 5-6 Tahun Di Desa Linawan Kecamatan Pinolosian Kabupaten Bolaang Mongondow Selatan. JURNAL KEPERAWATAN, 5(1).

[4] Kurniawan, S., \& Waluyo, B. (2018). Analisis Pengaruh Toolpath Pada Pembuatan Kacamata Kayu Dengan Mesin CNC Milling Router 3 Axis (Doctoral dissertation, Universitas Muhammadiyah Surakarta). 